\title{
African Kaposi's Sarcoma
}

\section{Sarcoma de Kaposi Africano}

Rita PIMENTA $\triangle 1$, Inês FONSECA ${ }^{2}$, João BORGES-COSTA ${ }^{1,3,4}$ Acta Med Port 2018 Nov;31(11):697-697 - https://doi.org/10.20344/amp.9754

Keywords: Africa; Sarcoma, Kaposi; Skin Manifestations

Palavras-chave: Africa; Manifestações Cutâneas; Sarcoma de Kaposi

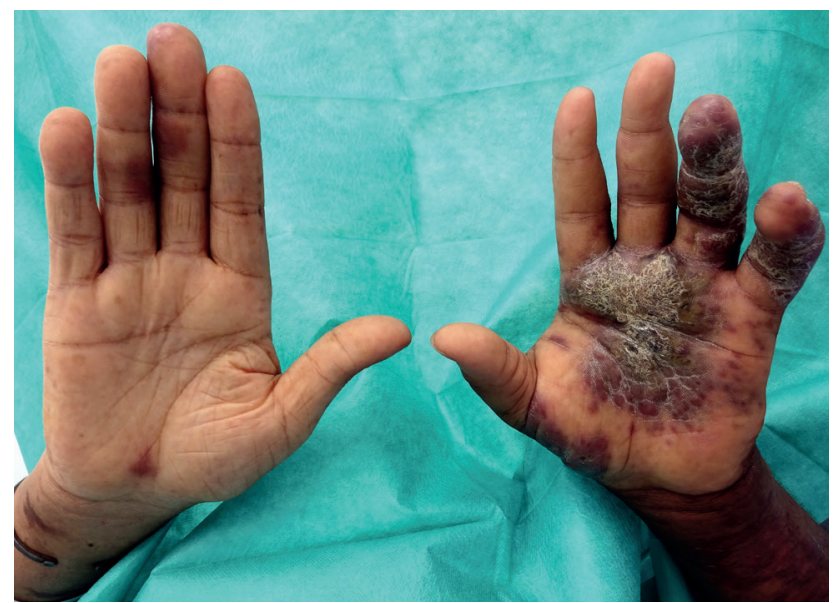

Figure 1 - Multiple erythematous-violaceous plaques both palms

A 45-year-old Guinean man, who had come to Portugal under a Health Cooperation Protocol, presented with a sixmonth history of progressively enlarging, violaceous infiltrative nodules and plaques on both the upper and lower limbs (Fig. 1). Extensive swelling and hyperkeratotic plaques of both feet were also observed (Fig. 2). The histopathological study confirmed the diagnosis of Kaposi sarcoma (KS). Serologies for HIV 1 and 2 were negative, and imaging studies ruled out systemic disease. The patient started chemotherapy with liposomal doxorubicin but he subsequently

\section{PROTECTION OF HUMANS AND ANIMALS}

The authors declare that the procedures were followed according to the regulations established by the Clinical Research and Ethics Committee and to the Helsinki Declaration of the World Medical Association.

\section{DATA CONFIDENTIALITY}

The authors declare having followed the protocols in use at their working center regarding patients' data publication.

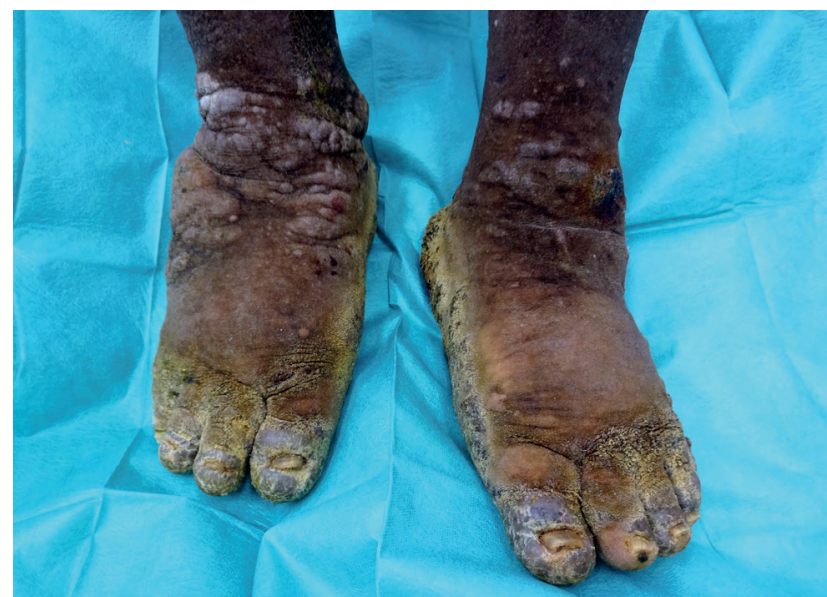

Figure 2 - Swelling and hyperkeratotic plaques on both feet developed acute heart failure and died.

Kaposi's sarcoma is a vascular malignancy that affects primarily the skin. ${ }^{1}$ African or endemic KS, rare in Portugal, ${ }^{2}$ is most commonly found in sub-Saharan Africa. ${ }^{1}$ This variant is not related to HIV infection and runs a more aggressive and faster course with wide skin involvement. ${ }^{3}$

\section{ACKNOWLEDGMENT}

We thank Luís Soares de Almeida for his contribution in the histological examination.

\section{PATIENT CONSENT}

Obtained.

\section{CONFLICTS OF INTEREST}

All authors report no conflict of interest.

\section{FUNDING SOURCES}

None.

\section{REFERENCES}

1. Curtiss P, Strazzulla LC, Friedman-Kien AE. An update on Kaposi's sarcoma: epidemiology, pathogenesis and treatment. Dermatol Ther. 2016;6:465-70

2. Travassos R, Borges-Costa J, Uva L. Endemic African Kaposi's sarcoma: a description of the clinical features and therapeutic options in three patients. Skin Cancer. 2010;25:109-16.

3. Schneider JW, Dittmer DP. Diagnosis and treatment of Kaposi sarcoma. Am J Clin Dermatol. 2017;18:529-39.

1. Department of Dermatology. Santa Maria University Hospital. Lisbon. Portugal.

2. Department of Internal Medicine. Santa Maria University Hospital. Lisbon. Portugal.

3. Institute for Hygiene and Tropical Medicine. Universidade NOVA. Lisbon. Portugal.

4. Faculdade de Medicina. Universidade de Lisboa. Lisboa. Portugal.

$\triangle$ Autor correspondente: Rita Pimenta. ritapimenta@campus.ul.pt

Recebido: 03 de outubro de 2017 - Aceite: 28 de maio de 2018 | Copyright @ Ordem dos Médicos 2018 